\title{
CHARACTERIZATION OF HYBRID FERROELECTRIC/HTS THIN FILMS FOR TUNABLE MICROWAVE COMPONENTS
}

\author{
M.D. Winters ${ }^{1 \dagger}$, C.H. Mueller ${ }^{2}$, K.B. Bhasin ${ }^{1}$, and F.A. Miranda ${ }^{1}$ \\ ${ }^{1}$ National Aeronautics and Space Administration \\ Lewis Research Center \\ Cleveland, OH, 44135, U.S.A. \\ ${ }^{2}$ Superconducting Core Technologies, Inc. \\ Golden, CO, 80401, U.S.A.
}

\begin{abstract}
Since the discovery of High-Temperature-Superconductors (HTS) in 1986, a diversity of HTS-based microwave components has been demonstrated. Because of their low conductor losses, HTS-based components are very attractive for integration into microwave circuits for space communication systems. Recent advancements have made deposition of ferroelectric thin films onto HTS thin films possible. Due to the sensitivity of the ferroelectric's dielectric constant $\left(\epsilon_{\mathrm{r}}\right)$ to an externally applied electric field $(\mathbf{E})$, ferroelectric/superconducting structures could be used in the fabrication of low loss, tunable microwave components. In this paper, we report on our study of $\mathrm{Ba}_{0.5} \mathrm{Sr}_{0.5} \mathrm{TiO}_{3} / \mathrm{YBa}_{2} \mathrm{Cu}_{3} \mathrm{O}_{7-\delta}$ and $\mathrm{Ba}_{0.08} \mathrm{Sr}_{0.92} \mathrm{TiO}_{3} / \mathrm{YBa}_{2} \mathrm{Cu}_{3} \mathrm{O}_{7-\delta}$ ferroelectric/superconducting thin films on lanthanum aluminate $\left(\mathrm{LaAlO}_{3}\right)$ substrates. For the (Ba:Sr, 0.50:0.50) epitaxial sample, a $\epsilon_{\mathrm{r}}$ of 425 and a loss tangent $(\tan \delta)$ of 0.040 were measured at $298 \mathrm{~K}, 1.0 \mathrm{MHz}$, and zero applied E. For the same sample, a $\epsilon_{\mathrm{r}}$ of 360 and $\tan \delta$ of 0.036 were obtained at $77 \mathrm{~K}, 1.0 \mathrm{MHz}$, and zero applied $\mathbf{E}$. Variations in $\epsilon_{\mathrm{r}}$ from 180 to 360 were observed over an applied $\mathbf{E}$ range of $0 \mathrm{~V} / \mathrm{cm} \leq \mathbf{E} \leq 5.62 \times 10^{4} \mathrm{~V} / \mathrm{cm}$ with little change in $\tan \delta$. However, the range of $\epsilon_{\mathrm{r}}$ variation for the polycrystalline (Ba:Sr, 0.08:0.92) sample over $0 \mathrm{~V} / \mathrm{cm} \leq \mathbf{E} \leq 4.00 \times 10^{4} \mathrm{~V} / \mathrm{cm}$ was only 3.6 percent while tan $\delta$ increased markedly. These results indicate that a lack of epitaxy between the ferroelectric and superconducting layers decreases tuning and increases microwave losses.
\end{abstract}

${ }^{\dagger}$ FJFP/NASA summer intern; Department of Electrical Engineering, Cornell University, Ithaca, NY, 14853, U.S.A. 


\section{INTRODUCTION}

Since the discovery of High-Temperature-Superconductors (HTS) in 1986, it has been possible to fabricate HTS-based planar microwave components such as resonators and filters ${ }^{1}$. The use of HTS films in place of normal conductors (e.g. gold and copper) has greatly reduced conductor losses and consequently insertion losses ${ }^{2}$. Therefore, significant attention has been given to the quality and processing of HTS films as efforts continue towards the inclusion of HTS-based circuits in working systems. One of the areas that has received considerable attention for the insertion of HTS-based components is that of tunable microwave circuits ${ }^{3}$. This requires the development of hybrid superconductor/ferroelectric structures. Ferroelectric materials have a dielectric constant $\left(\epsilon_{\mathrm{r}}\right)$ that can be altered by an externally applied electric field (E). Therefore, optimization of these structures' material properties and careful characterization of their electrical properties should result in high quality, low loss tunable microwave components, such as capacitors, filters, and phase shifters. In this paper, we report on our study of $\mathrm{Ba}_{0.5} \mathrm{Sr}_{0.5} \mathrm{TiO}_{3} / \mathrm{YBa}_{2} \mathrm{Cu}_{3} \mathrm{O}_{7-\delta}$ and $\mathrm{Ba}_{0.08} \mathrm{Sr}_{0.92} \mathrm{TiO}_{3} / \mathrm{YBa}_{2} \mathrm{Cu}_{3} \mathrm{O}_{7-\delta}$ ferroelectric/superconducting thin films on lanthanum aluminate $\left(\mathrm{LaAlO}_{3}\right)$ substrates.

\section{EXPERIMENTAL}

The $\mathrm{Ba}_{0.5} \mathrm{Sr}_{0.5} \mathrm{TiO}_{3} / \mathrm{YBa}_{2} \mathrm{Cu}_{3} \mathrm{O}_{7-\delta} / \mathrm{LaAlO}_{3}\left(\mathrm{BST} / \mathrm{YBCO} / \mathrm{LaAlO}_{3}\right)$ structure which was investigated consisted of an $800 \mathrm{~nm}$ thick $\mathrm{Ba}_{0.5} \mathrm{Sr}_{0.5} \mathrm{TiO}_{3}$ film, known hereinafter as BST, deposited on a $300 \mathrm{~nm}$ thick $\mathrm{YBa}_{2} \mathrm{Cu}_{3} \mathrm{O}_{7-\delta}$ film which coated a $5.0 \mathrm{~mm} \times 4.0 \mathrm{~mm} \times 0.50 \mathrm{~mm}$ $\mathrm{LaAlO}_{3}$ substrate. Both layers were deposited "in-situ" using laser ablation. To elucidate the effects of film microstructure on tuning and loss, metalorganic deposited $\mathrm{Ba}_{0.08} \mathrm{Sr}_{0.92} \mathrm{TiO}_{3}$ films, known hereinafter as MOD BST films, were prepared at room temperature and post annealed at $700^{\circ} \mathrm{C}$ to produce polycrystalline films ${ }^{4}$. After deposition of the multilayer structures,

(a)

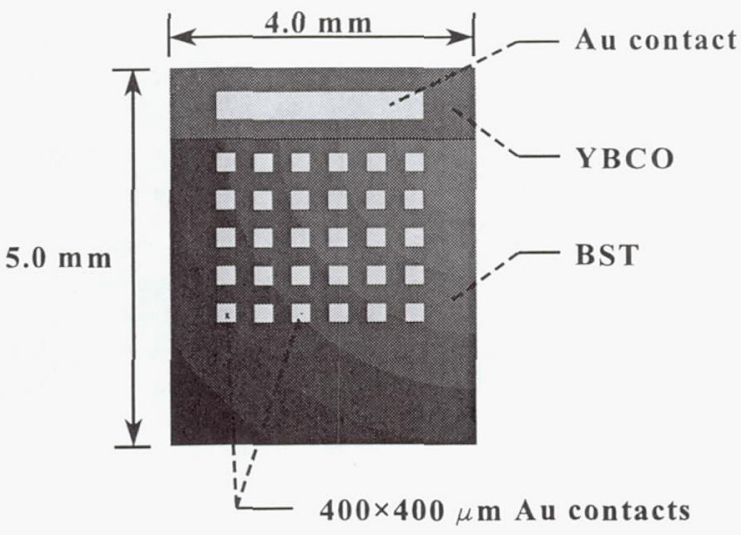

(b) Au contacts

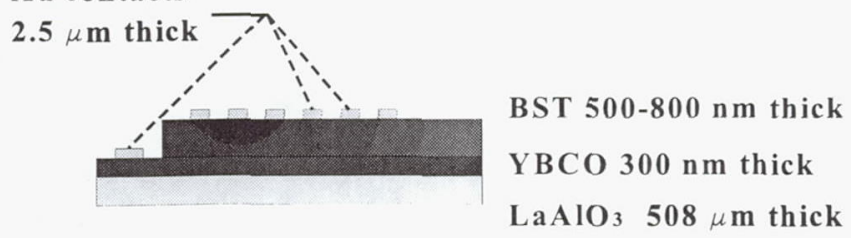

Figure 1. A schematic representation of the $\mathrm{Ba}_{\mathbf{x}} \mathrm{Sr}_{1-x} \mathrm{TiO}_{3}(\mathrm{x}=0.50,0.08) / \mathrm{YBa}_{2} \mathrm{Cu}_{3} \mathrm{O}_{7-8} / \mathrm{LaAlO}_{3}$ structure. (a) Top view, (b) Side view. 
(a)

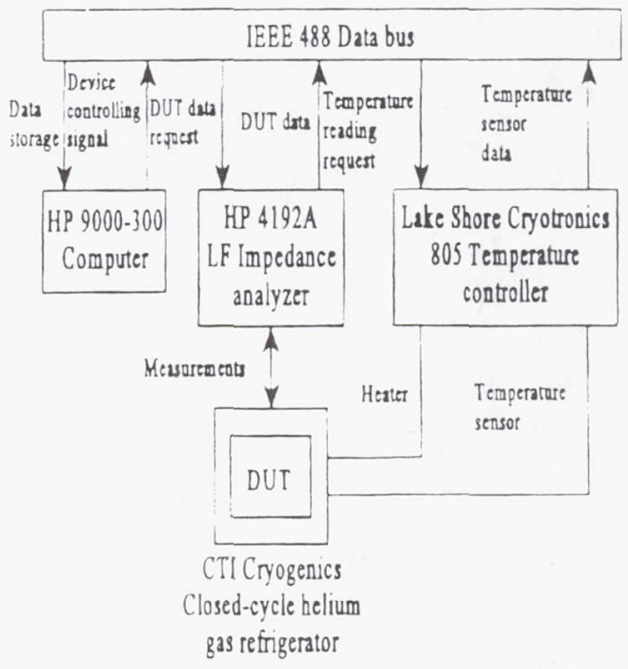

(b)

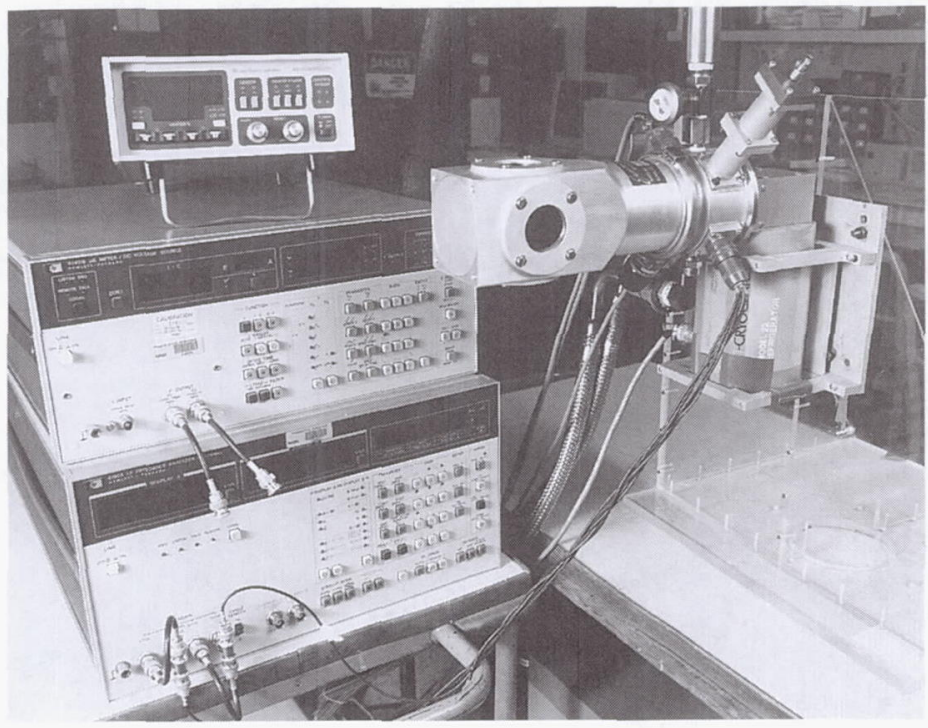

Figure 2. Experimental configuration. (a) Schematic representation, (b) Actual setup.

transition temperatures $\left(\mathrm{T}_{\mathrm{c}}\right)$ above $89 \mathrm{~K}$ were measured for the YBCO films using a four point probe technique indicating that no degradation of the these films occurred as a result of the ferroelectric film deposition. Thirty $400 \mu \mathrm{m} \times 400 \mu \mathrm{m} \times 2.5 \mu \mathrm{m}$ gold (Au) contacts were fabricated on the ferroelectric layer of the structures using standard photolithography and wet etching techniques. In addition, a Au electrode was deposited onto a portion of the structures' YBCO layer, exposed by etching the ferroelectric layer away with a 7.0 percent solution of hydrofluoric (HF) acid. Figure 1 shows a schematic representation of the aforementioned structures. This configuration was used to measure the capacitance (C) at $1.0 \mathrm{MHz}$ from which the $\epsilon_{\mathrm{r}}$ of the ferroelectric layer was thereby calculated using Eq. (1),

$$
\epsilon_{r}=\frac{C d}{\epsilon_{0} A}
$$




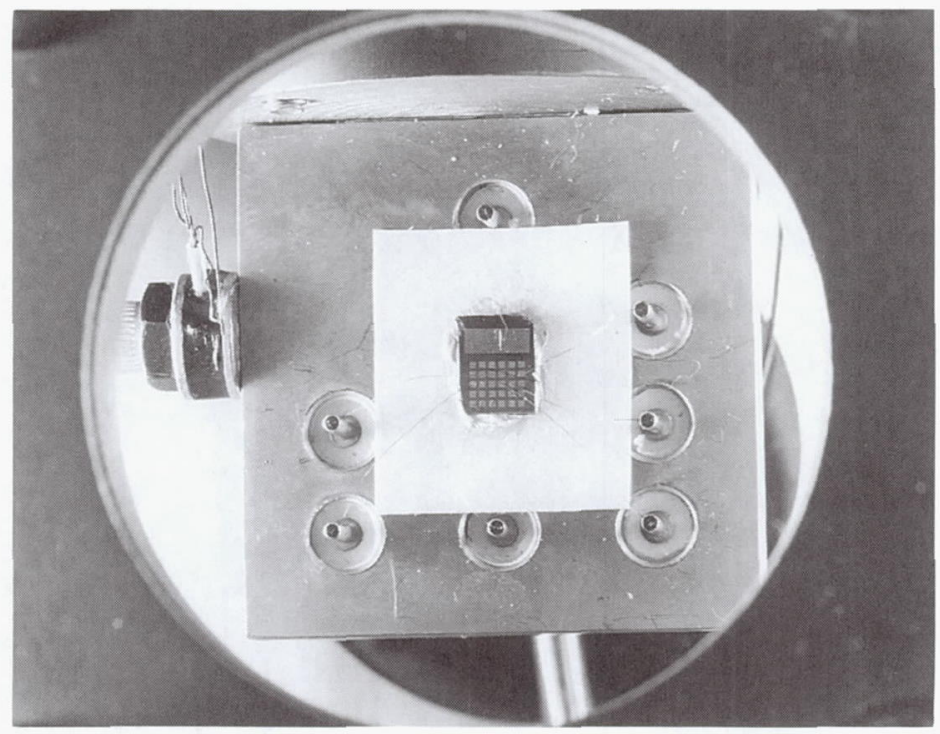

Figure 3. Sample mounted inside vacuum chamber showing electrical feedthroughs.

where A represents the area of the gold contact, $\mathrm{d}$ represents the thickness of the ferroelectric layer, and $\epsilon_{\mathrm{o}}=8.854 \times 10^{-12} \mathrm{~F} / \mathrm{m}$ represents the permitivity of free space.

Values of $\epsilon_{\mathrm{r}}$ for the ferroelectric layers were obtained as a function of temperature and dc bias. An HP-4192A LF impedance analyzer, a CTI-Cryogenics closed-cycle, helium gas refrigerator, and a Lake Shore Cryotronics 805 temperature controller all linked through an IEEE-488 data bus to an HP 9000-300 computer served as the main components of the experimental configuration, shown in Figure 2, which performed these measurements. As seen in Figure 3, the sample, known as the device-under-test (DUT), was mounted on a sample holder having electrical feedthroughs for dc bias. The temperature sensor, a silicon diode, was bolted directly to the sample holder. The sample holder was bolted to the cold head of the refrigerator to allow for measurements at cryogenic temperatures. An HP-Basic computer program was written to automate the measurement system allowing the user to take data as a function of temperature at a constant de voltage and as a function of de voltage at a constant temperature. All measurements were taken at "user-input" pre-selected conditions. Preselected dc voltage conditions were directly outputted to the impedance analyzer and

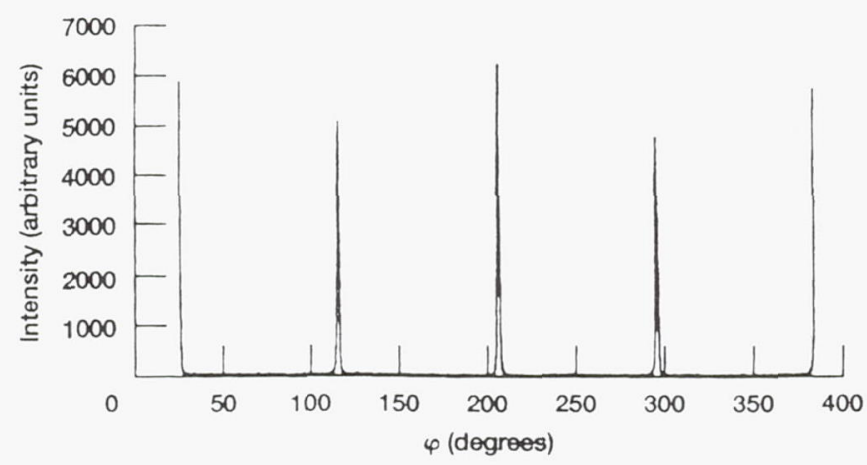

Figure 4. Phi scan about the BST (420) peak. Four-fold symmetry shows good in-plane alignment of the BST film on the YBCO film. 


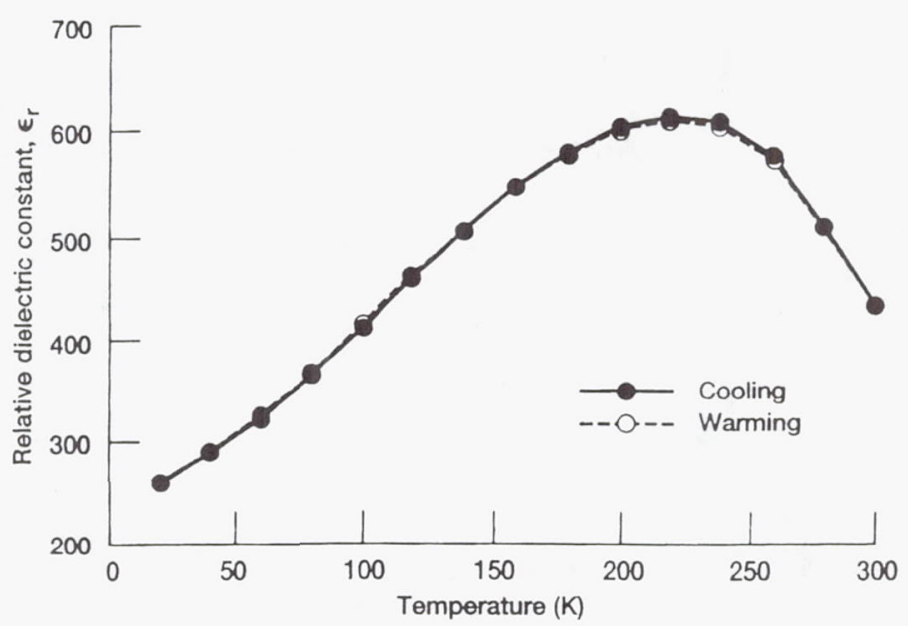

Figure 5. Dielectric constant versus temperature for the BST (Ba:Sr, 0.50:0.50) layer in the $\mathrm{BST} / \mathrm{YBCO} / \mathrm{LaAlO}_{3}$ structure at $1.0 \mathrm{MHz}$ and zero E.

temperatures conditions were outputted as "set-points" to the temperature controller which controlled and monitored the temperature of the DUT. When specified conditions were met, data on the DUT's capacitance and loss tangent $(\tan \delta)$ were measured by the impedance analyzer and stored along with the DUT's $\epsilon_{\mathrm{r}}$, calculated by the computer program using Eq. 1, to a 3.5 inch disk for further analysis.

\section{RESULTS}

The ferroelectric layers were analyzed using x-ray diffraction (XRD). As seen in Figure 4, Phi scans about the (420) peak of the BST film show in-plane epitaxy with the underlying YBCO film. However, diffraction peaks for the MOD BST film were very weak at high angles and there was no evidence of in-plane epitaxy.

For the electrical characterization of the samples, the first test undertaken focused on measuring $\epsilon_{\mathrm{r}}$ as a function of temperature at a frequency of $1.0 \mathrm{MHz}$ and at zero $\mathrm{E}$. Measurements were taken at intervals of $20 \mathrm{~K}$ during cooling from 300 to $20 \mathrm{~K}$ and during

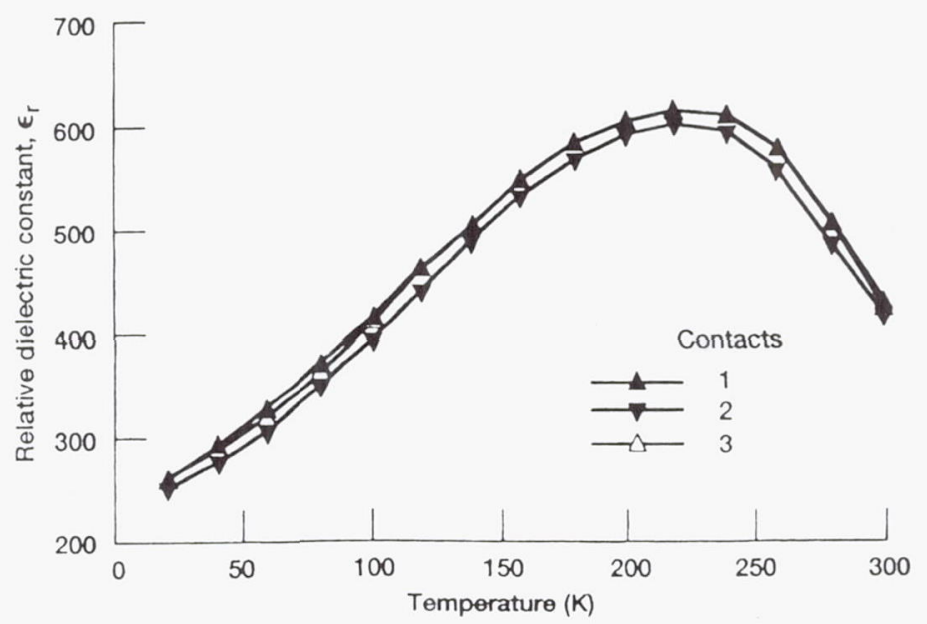

Figure 6. Dielectric constant values of different contacts versus temperature for the BST (Ba:Sr, 0.50:0.50) layer in the $\mathrm{BST} / \mathrm{YBCO} / \mathrm{LaAlO}_{3}$ structure at $1.0 \mathrm{MHz}$ and zero $\mathbf{E}$. 


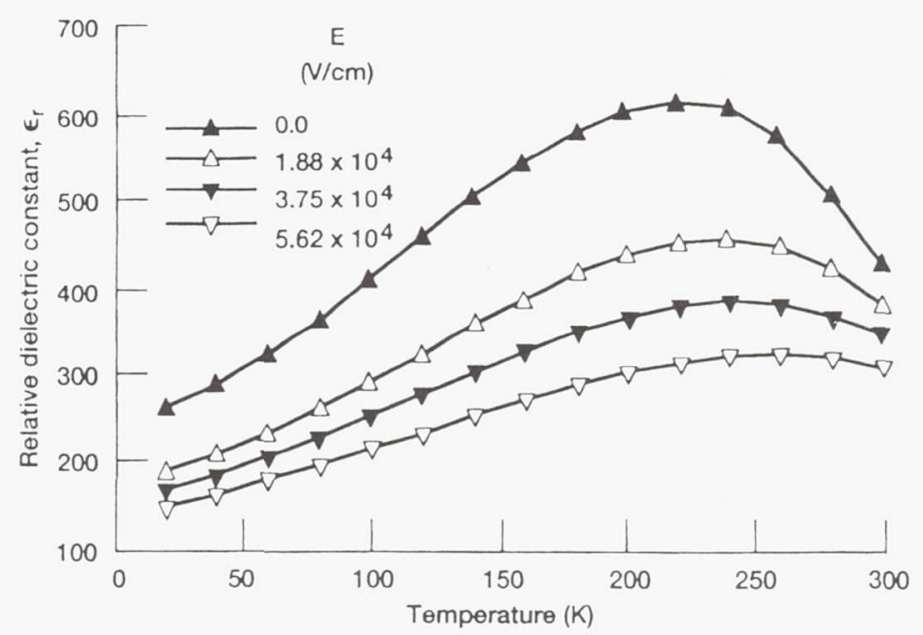

Figure 7. Dielectric constant versus temperature for the BST (Ba:Sr, 0.50:0.50) layer in the $\mathrm{BST} / \mathrm{YBCO} / \mathrm{LaAlO}_{3}$ structure at $1.0 \mathrm{MHz}$ and several values of $\mathbf{E}$.

warming from 20 to $300 \mathrm{~K}$ to determine if the samples were sensitive to the temperature cycling. At room temperature, values of $\epsilon_{\mathrm{r}}$ and $\tan \delta$ for the BST sample of 425 and 0.040 , respectively, were obtained. Neither the $\epsilon_{\mathrm{r}}$ data, seen in Figure 5, nor the $\tan \delta$ data showed any signs of temperature hysteresis as a result of the temperature cycling. Figure 6 shows $\epsilon_{\mathrm{t}}$ data from different contacts across the sample's surface taken under the same temperature and bias conditions. This test was performed to determine the degree of uniformity of the BST film. Note that the obtained results are quantitatively and qualitatively very similar. This suggests excellent composition and structural (i.e., thickness) uniformity throughout the BST layer. The behavior of $\epsilon_{\mathrm{r}}$ and $\tan \delta$ as a function of $\mathbf{E}$ was also investigated. The results are shown in Figure 7 and Figure 8. In Figure 7, each curve represents the $\epsilon_{\mathrm{r}}$ of the BST layer as a function of temperature at a particular $\mathbf{E}$ value. Note that there is a decrease in $\epsilon_{\mathrm{r}}$ as the magnitude of the applied field is increased. Maximum variation in $\epsilon_{\mathrm{r}}$, from $\epsilon_{\mathrm{r}}=610$ to $\epsilon_{\mathrm{r}}=300$, occurred at a temperature near $220 \mathrm{~K}$. For practical microwave components, such as tunable

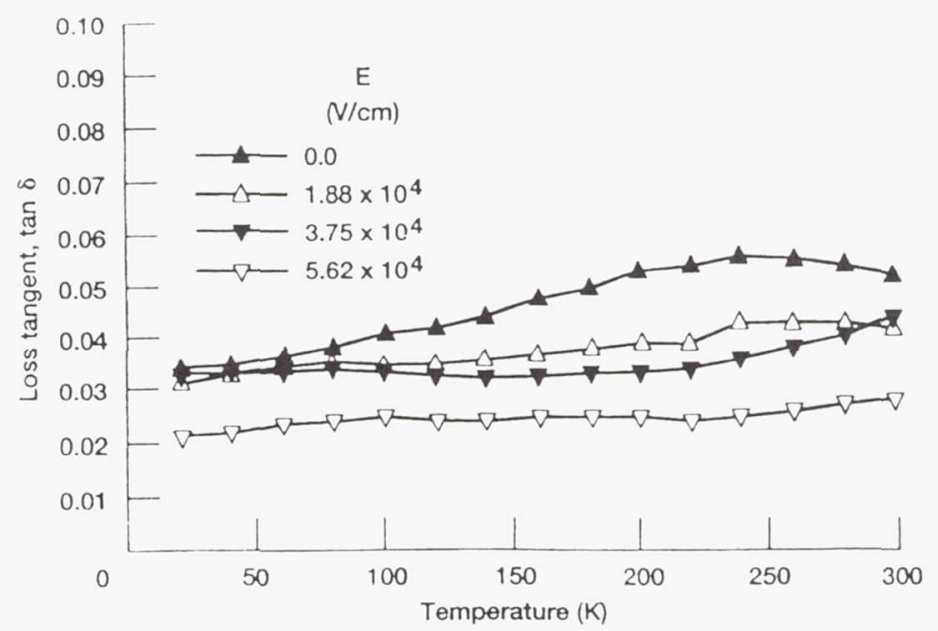

Figure 8. Loss tangent versus temperature for the BST (Ba:Sr, 0.50:0.50) layer in the $\mathrm{BST} / \mathrm{YBCO} / \mathrm{LaAlO}_{3}$ structure at $1.0 \mathrm{MHz}$ and several values of $\mathbf{E}$. 


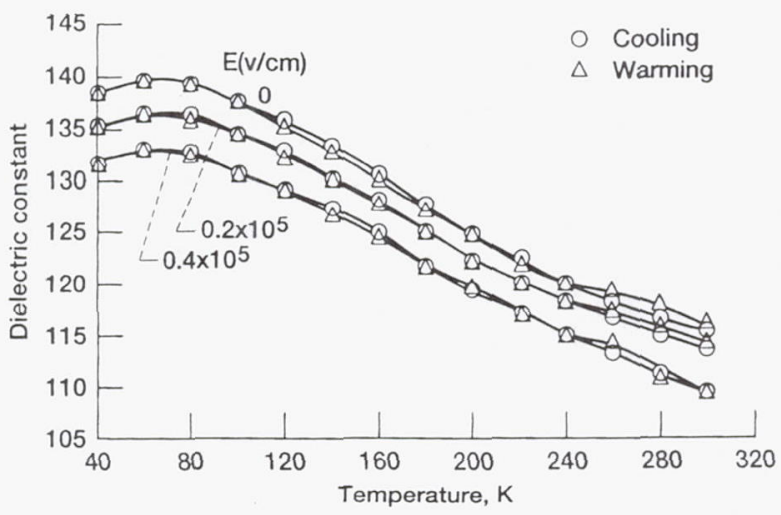

Figure 9. Dielectric constant versus temperature for a polycrystalline, $500 \mathrm{~nm}$ thick, metalorganic deposited MOD BST (Ba:Sr, 0.08:0.92) layer in the $\mathrm{BST} / \mathrm{YBCO} / \mathrm{LaAlO}_{3}$ structure at $1.0 \mathrm{MHz}$ and several values of $\mathbf{E}$.

capacitors, filters, and phase shifters, a change in $\epsilon_{\mathrm{r}}$ from 300 to 610 will create a frequency range within which the component can be tuned ${ }^{5-7}$. At $77 \mathrm{~K}$, a temperature at which YBCO is in the superconducting state, values of $\epsilon_{\mathrm{r}}$ changed from 180 to 360 in the range of $0 \mathrm{~V} / \mathrm{cm} \leq \mathbf{E} \leq 5.62 \times 10^{4} \mathrm{~V} / \mathrm{cm}$. At this temperature, both the HTS film's low conductor losses as well as the ferroelectric's tunability could be fully exploited.

Figure 8 shows results of $\tan \delta$ as a function of temperature and $\mathbf{E}$. It can be seen that the values for $\tan \delta$ vary slightly as a function of $\mathbf{E}$ in the aforementioned field range. This result is very important for microwave applications since it shows that the $\epsilon_{\mathrm{r}}$ can be altered without dramatically enhancing the ferroelectric's microwave losses. The range of tunability for the polycrystalline, $500 \mathrm{~nm}$ thick, MOD BST film over $0 \mathrm{~V} / \mathrm{cm} \leq \mathbf{E} \leq 4.0 \times 10^{4} \mathrm{~V} / \mathrm{cm}$ at $60 \mathrm{~K}$ was only 3.6 percent, see Figure 9. In addition, $\tan \delta$ was very sensitive to $\mathbf{E}$ as shown in Figure 10. We dismiss the possibility that the lower tuning in the MOD BST film is due to the composition differences since measurements on epitaxial $\mathrm{STO}$ and $\mathrm{Ba}_{0.10} \mathrm{Sr}_{0.90} \mathrm{TiO}_{3}$ films deposited on YBCO displayed $\epsilon_{\mathrm{r}}$ values that could be decreased by 30 and 10 percent respectively under the same electric field ${ }^{8}$. Therefore, the fact that the tuning was lower for the MOD BST film suggests that the lack of epitaxy decreases tuning and also increases microwave losses.

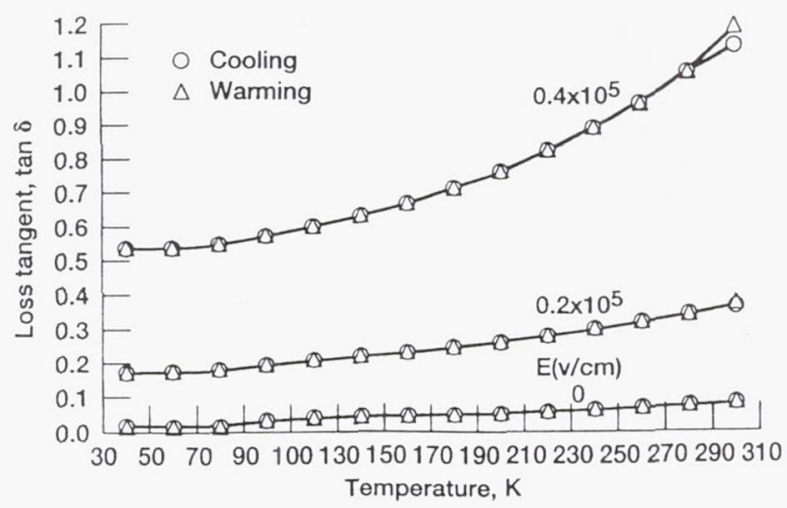

Figure 10. Loss tangent versus temperature for a polycrystalline, $500 \mathrm{~nm}$ thick, metalorganic deposited MOD

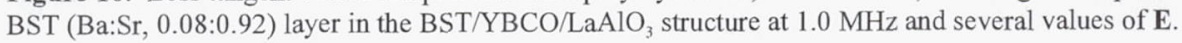




\section{CONCLUSION}

$\mathrm{A} \epsilon_{\mathrm{r}}$ of 425 and a $\tan \delta$ of 0.040 were measured at $298 \mathrm{~K}, 1.0 \mathrm{MHz}$, and zero $\mathbf{E}$ for an epitaxial BST ferroelectric layer. At $77 \mathrm{~K}, 1.0 \mathrm{MHz}$, and zero $\mathbf{E}$, a $\epsilon_{\mathrm{r}}$ of 360 and a tan $\delta$ of 0.036 were measured. Maximum change in $\epsilon_{\mathrm{r}}$, from 300 to 610 , was observed at $220 \mathrm{~K}$ in the $\mathbf{E}$ range of $0 \mathrm{~V} / \mathrm{cm} \leq \mathbf{E} \leq 5.62 \times 10^{4} \mathrm{~V} / \mathrm{cm}$ with minimal change in $\tan \delta$. The range of tunability for a polycrystalline, $500 \mathrm{~nm}$ thick, MOD BST film was very small, 3.6 percent, and $\tan \delta$ increased markedly with $\mathbf{E}$ over $0 \mathrm{~V} / \mathrm{cm} \leq \mathbf{E} \leq 4.0 \times 10^{4} \mathrm{~V} / \mathrm{cm}$. This suggests that the lack of epitaxy could adversely affect the tuning range and the microwave losses of ferroelectric/HTS based microwave components.

\section{ACKNOWLEDGMENTS}

The authors wish to thank Dr. R. Singh from the University of Florida at Gainesville for the fabrication of the laser ablated $\mathrm{BST} / \mathrm{YBCO} / \mathrm{LaAlO}_{3}$ structure and NIST-Boulder for the use of their X-ray diffraction equipment. The authors are grateful to Mr. Nick Varaljay and Ms. Donna Bohman for patterning the BST and MOD BST samples and Mr. Joseph Meola for assisting with the electrical measurements. The authors are grateful to the referees for their constructive comments and suggestions.

\section{REFERENCES}

1. F.A. Miranda, S.S. Toncich, and K.B. Bhasin, Performance of two-pole bandpass filters photodefined on double-sided Y-Ba-Cu-O and Tl-Ba-Ca-Cu-O thin films, Microwave and Optical Tech. Lett. 6:752-755 (1993).

2. F.A. Miranda, Microwave properties of Tl-Ba-Ca-Cu-O thin films, Supercond. Sci. Technol. 6:605-612 (1993).

3. A.M. Hermann, A. Naziripour, A. Outzourhit, and C.H. Mueller, Tunable microwave resonators based on sputtered Tl-Ba-Ca-Cu-O and Ba-Sr-Ti-O thin films, in: "Low Temperature Electronics and High Temperature Superconductivity," C.L. Claeys, ed., The Electrochemical Society, Inc., Pennington (1995), p. 35.

4. H.D. Wu, Z. Zheng, F. Barnes, C.H. Jackson, A. Kain, and J.D. Cuchiaro, Voltage tunable capacitors using high temperature superconductors and ferroelectrics, IEEE Trans. Appl. Superconductivity 4:156-160 (1994).

5. O.G.Vendik, L.T.Ter-Martirosyan, A.I.Dedyk, S.F.Karmanenko, and R.A.Chakalov, High-T, Superconductivity: New Applications of Ferroelectrics at Microwave Frequencies, Ferroelectrics 144:33-43 (1993).

6. S.S.Gevorgian, D.I.Kaparkov, and O.G.Vendik, Electrically Controlled HTSC/Ferroelectric Coplanar Waveguide, IEE Proc. Microwave Antennas Propagation 141:501-503 (1994).

7. O.G.Vendik, I.Mironenko, and L.T.Ter-Martirosyan, Superconductors Spur Applications of Ferroelectric Films, Microwaves and RF, 67-70 (July, 1994).

8. F.A. Miranda, C.H. Mueller, G.A. Koepf, and R.M. Yandrofski, Electrical response of ferroelectric/superconducting/dielectric $\mathrm{Ba}_{\mathrm{x}} \mathrm{Sr}_{1-\mathrm{x}} \mathrm{TiO}_{3} / \mathrm{YBa}_{2} \mathrm{Cu}_{3} \mathrm{O}_{7-8} / \mathrm{LaAlO}_{3}$ thin film multilayer structures, Supercond. Sci. Technol. 8:755-763 (1995). 